\title{
The use of rocuronium 20 minutes after sugammadex administration - a case report
}

\author{
Cátia Real, Jorge Silva, Simão Esteves and Humberto S Machado* \\ Department of Anesthesiology, Centro Hospitalar do Porto, Largo Professor Abel Salazar, 4099-001 Porto, Portugal
}

\begin{abstract}
Sugammadex has proven to be highly effective for the reversal of moderate or deep neuro $\neg$ muscular blockade induced by rocuronium or vecuronium. We present a case where optimal conditions for tracheal intubation were attained using rocuronium $\left(0.5 \mathrm{mg} \mathrm{kg}^{-1}\right) 20$ minutes (min) after sugammadex had been given. A 59-yr-old female patient, ASA II was scheduled for elective total thyroidectomy. Anesthesia included propofol, fentanyl and rocuronium with sugammadex for neuromuscular blockade reversal, and sevoflurane/air for maintenance. 20 minutes after reversal of neuromuscular blockade with sugammadex the patient returned to operating room for evacuation of cervical hematoma and second general anesthesia was induced with the usage of rocuronium $\left(0.5 \mathrm{mg} \mathrm{kg}^{-1}\right)$ and propofol $2 \mathrm{mg} \mathrm{kg}{ }^{-1}$. Good intubation conditions were obtained after approximately 2 minutes and tracheal intubation was performed uneventfully without any observed desaturation below $96 \%$. Patient returned to post anesthesia care unit after the second procedure, well and fully recovered, and had hospital discharge after 3 days.
\end{abstract}

Our case shows that a short time of twenty minutes between use of sugammadex and rocuronium $\left(0.5 \mathrm{mg} \mathrm{kg}{ }^{-1}\right)$ did not affect intubation conditions, with normal induction doses of propofol.

\section{Introduction}

Sugammadex, a modified $\gamma$-cyclodextrin, has proven to be highly effective for the reversal of moderate or deep neuromuscular blockade induced by rocuronium or vecuronium [1]. Sugammadex has revolutionized post-operative care due to its capability to reverse neuromuscular blockade (NMB) safely, rapidly and efficiently.

Although uncommon, patients may require anesthesia and tracheal intubation in the immediate postoperative period, soon after successful reversal of rocuronium-induced NMB by sugammadex. One of the options in such situations would be to re-administer rocuronium. We present a case where optimal conditions for tracheal intubation were attained using rocuronium $\left(0.5 \mathrm{mg} \mathrm{kg}^{-1}\right) 20$ minutes $(\mathrm{min})$ after sugammadex had been given. The patient granted written consent for publication of the manuscript.

\section{Materials and methods}

A 59-yr-old female patient, American Society of Anesthesiologists Physical Status II (hypothyroidism), weight $60 \mathrm{~kg}$, height $160 \mathrm{~cm}$ and body mass index $23.4 \mathrm{~kg} \mathrm{~m}^{-2}$ was scheduled for elective total thyroidectomy. The only drug usually taken was sodium levothyroxine. Laboratory values where within normal limits.

Intraoperative monitors included electrocardiogram, non-invasive blood pressure, pulse oxymetry and end-tidal $\mathrm{CO}_{2}$. Temperature was not monitored. Following preoxygenation, general anesthesia was induced with fentanyl $150 \mu \mathrm{g}$, propofol $150 \mathrm{mg}$ and rocuronium $50 \mathrm{mg}(0.83 \mathrm{mg}$ $\left.\mathrm{kg}^{-1}\right)$ to facilitate tracheal intubation. Anesthesia was maintained with sevoflurane and fentanyl. Neuromuscular function was monitored with NMT MechanoSensor monitor using repetitive train-of-four (TOF) stimulation of the ulnar nerve (NMT Mechanosensor ${ }^{\infty}$, Datex Ohmeda Division, Finland).

Surgery was uneventful and lasted $79 \mathrm{~min}$. Postoperative analgesia was started during the procedure with tramadol $100 \mathrm{mg}$ and paracetamol $1 \mathrm{~g}$. Postoperative nausea and vomiting prophylaxis was provided with dexamethasone $4 \mathrm{mg}$ and droperidol $0.625 \mathrm{mg}$. The antibiotic prophylaxis was made with cefazolin $2 \mathrm{~g}$.

At the end of the procedure and about $80 \mathrm{~min}$ after rocuronium was administered there were two twitches to TOF stimulation. The $\mathrm{NMB}$ was antagonized with sugammadex $150 \mathrm{mg}\left(2.5 \mathrm{mg} \mathrm{kg}^{-1}\right)$ and the patient's trachea was extubated when the TOF reached the value of 1 .

Almost immediately after the patient being admitted in the post anesthesia care unit (PACU), she developed an expanding neck hematoma without airway compromise and was brought back to the operating room for hematoma evacuation. A second round of general anesthesia was performed $20 \mathrm{~min}$ after the previous dose of sugammadex with fentanyl $100 \mu \mathrm{g}$, propofol $100 \mathrm{mg}$ and rocuronium $30 \mathrm{mg}\left(0.5 \mathrm{mg} \mathrm{kg}^{-1}\right)$, and the same monitors were applied.

Endotracheal intubation was performed approximately 2 minutes and 30 seconds ( $\mathrm{sec}$ ) after rocuronium. Despite the fact that a TOF of 0.6 was still registered, optimal conditions for intubation were encountered and intubation was performed without difficulty. Rocuronium time of administration to maximum effect (onset time) was about $7 \mathrm{~min}$. The second surgery procedure took 34 minutes to be completed. About 40 min after the second dose of rocuronium, TOF was 0.1 and sugammadex $200 \mathrm{mg}\left(3.3 \mathrm{mg} \mathrm{kg}^{-1}\right)$ was again administered. Extubation was carried out after consciousness and regular, spontaneous respirations resumed.

Correspondence to: Humberto S Machado, Department of Anesthesiology, Centro Hospitalar do Porto, Largo Professor Abel Salazar, 4099-001 Porto, Portugal, Tel: +351 935848475; E-mail: hjs.machado@gmail.com

Received: August 05, 2015; Accepted: August 28, 2015; Published: September 02,2015 
The patient's remaining hospital course was uneventful and the patient was discharged.

\section{Discussion}

When sugammadex is administered it decreases rocuronium plasma concentration by promptly binding to free rocuronium molecules in the plasma. A rocuronium concentration gradient forms between plasma and neuromuscular junction allowing rocuronium to move from the neuromuscular junction to the plasma where it continues to form rocuronium-sugammadex complexes [2]. Evidence advocates that these complexes remain stable over time.

There are multiple options available to manage $\mathrm{NMB}$ when surgical reintervention is needed after sugammadex administration: the use of succinylcholine; the use of a benzylisoquinoline muscle relaxant (atracurium, cisatracurium, or mivacurium); or a second use of rocuronium [3]. Despite the continuing debate, it is still not clear which one is the best option [4,5]. When the option, after administering sugammadex (up to $4 \mathrm{mg} \mathrm{kg}^{-1}$ ) is to use rocuronium the recommendations are as follows: $0.6 \mathrm{mg} \mathrm{kg}^{-1}$ and $1.2 \mathrm{mg} \mathrm{kg}^{-1}, 4$ hours and $5 \mathrm{~min}$, respectively, after using sugammadex [6].

In our case, the subsequent dose of rocuronium $0.5 \mathrm{mg} \mathrm{kg} \mathrm{kg}^{-1}$ was given $20 \mathrm{~min}$ after a dose of sugammadex, and it produced an effect with a slower onset time (approximately $7 \mathrm{~min}$ ) that would be expected under usual circumstances. Likewise, other authors reported cases where doses of rocuronium after sugammadex lower than the recommended ones produced slower NMB onset time. Fabregat-Lopez et al. reported a case where rocuronium-induced NMB $\left(0.53 \mathrm{mg} \mathrm{kg}^{-1}\right)$ was achieved $143 \mathrm{~min}$ after sugammadex $\left(4.2 \mathrm{mg} \mathrm{kg}^{-1}\right)$ had been given [4]. However, the effect produced was less intense ( $86 \% \mathrm{~T} 1 \mathrm{block})$ and had a slower onset time than would normally be expected, upon which another $10 \mathrm{mg}$ of rocuronium were added. On the other hand, Matsuki et al. reported a case where rocuronium $1 \mathrm{mg} \mathrm{kg}^{-1}$ administered $19 \mathrm{~min}$ later after sugammadex $2.75 \mathrm{mg} \mathrm{kg}^{-1}$, in a patient under sevoflurane anesthesia, was unable to induce muscular relaxationand an additional $30 \mathrm{mg}$ were required [7].

Cammu et al. designed a study to evaluate the onset times and the clinical duration of NMB induced by $1.2 \mathrm{mg} \mathrm{kg}^{-1}$ rocuronium administered at variables times after $4.0 \mathrm{mg} \mathrm{kg}^{-1}$ sugammadex had been given. This study was performed in healthy volunteers under propofol anesthesia [8]. Rapid re-onset of NMB occurred after repeat dosing of rocuronium as early as $5 \mathrm{~min}$ after sugammadex. Therefore, it is possible to induce a complete NMB by increasing the second rocuronium dose even immediately after sugammadex administration. They found an inverse relationship between the onset time and the time interval between sugammadex and repeat dosing of rocuronium. Cammu et al. also observed that the shorter the interval between a sugammadex and rocuronium, the shorter would be the NMB duration [8]. This can be explained by the presence of significant amounts of free sugammadex that remains available to reverse the second dose of rocuronium.

The clinical duration (duration from the initial administration to spontaneous recovery to $25 \%$ of control twitch height) with $0.6 \mathrm{mg}$ $\mathrm{kg}^{-1}$ rocuronium bromide is 30 to $40 \mathrm{~min}$ [9]. In the presented case the clinical duration was within the range of what was expected for the repeat dosing of rocuronium (about $30 \mathrm{~min}$ ), as were the observations of Matsuki et al. [7]. These authors reported the re-appearance of T1 $64 \mathrm{~min}$ after re-administration of rocuronium $1 \mathrm{mg} \mathrm{kg}^{-1}$ being administered 19 min later after sugammadex. They attributed the lack of consistency of their observations with the results of Cammu et al. [8] to the anesthetic technique, namely the sevoflurane. Inhaled anesthetics enhance the neuromuscular blocking effects of nondepolarizing neuromuscular blockers. Sevoflurane may also have prolonged the duration of action of the second dose of rocuronium in our case.

Nonetheless, the onset time and duration of action of a second dose of rocuronium following the administration of sugammadex are unpredictable due to the dose of rocuronium, the previous dose of sugammadex and the duration of time between the administrations of these two drugs, among others [10]. This might indicate that in this setting depolarizing NMB agents and benzylisoquinoline muscle relaxants would be more appropriate choices.Bom et al. reported, in an animal study, a small delay in the onset time but a normal speed of recovery when succinylcholine was administered 3 minutes after reversing the rocuronium-induced NMB with sugammadex [11]. The same study reported a normal speed of onset and recovery when cisatracurium was used instead of a depolarizing NMB agent, in the same circumstances. Unfortunately, studies involving the use of depolarizing and benzylisoquinoline neuromuscular blockers following the administration of sugammadex are limited and additional studies on the changes of the pharmacokinetics of these drugs are required.

If the option is to re-administer rocuronium the dose chosen should also have into account the patient and the clinical context in place. If the patient doesn't have a significant risk of regurgitation and the surgical procedure doesn't qualifies as an emergent one, a smaller dose of rocuronium than the one recommended could be given at the time of the induction of anesthesia and if necessary adjusted posteriorly.

One of the clear indications for the use of muscle relaxants in anesthesia practice is to facilitate laryngoscopy and tracheal intubation, though this can be accomplished without NMB agents. Barclay et al. assessed three factors when evaluating conditions for tracheal intubation: ease of jaw opening and laryngoscopy, position of the vocal cords and their movement and degree of straining after tracheal intubation and cuff inflation [12]. Tracheal intubation was considered optimal when jaw opening and laryngoscopy was not difficult, vocal cords were not closed and if straining occurred after tracheal intubation and cuff inflation would not involve the abdominal muscles. In this case, optimal tracheal intubation conditions were considered to exist even though the TOF was about 0.6 since all of the requirements above were verified.

\section{Conclusion}

1) A short time of twenty minutes between use of sugammadex and rocuronium may not affect intubation conditions, with normal induction propofol doses.

2) Neuromuscular monitoring is, in every case, mandatory to adequately assess the NMB of the individual patient and doses of rocuronium and sugammadex should be tailored to the clinical context.

3) More studies to analyze the pharmacokinetic and pharmacodynamic profile of repeated administration of rocuronium and sugammadex are in need.

\section{References}

1. Mirakhur RK (2009) Sugammadex in clinical practice. Anaesthesia 64 Suppl 1: 45-54 [Crossref]

2. Akha AS, Rosa J, Jahr JS, Li A, Kiai K (2010) Sugammadex: cyclodextrins, development of selective binding agents, pharmacology, clinical development, and future directions. Anesthesiol Clin 28: 691-708. [Crossref] 
3. Schaller SJ, Fink H (2013) Sugammadex as a reversal agent for neuromuscular block: an evidence-based review. Core Evid 8: 57-67. [Crossref]

4. Fabregat-López J, Veiga-Ruiz G, Dominguez-Serrano N, García-Martinez MR (2011) Re-establishment of neuromuscular block by rocuronium after sugammadex administration. Can J Anaesth 58: 658-659.

5. Harris P (2011) Unexpected failure of rocuronium-mediated neuromuscular blockade. Anaesthesia 66: 525. [Crossref]

6. http://www.ema.europa.eu/docs/en_GB/document_library/EPAR_Product_ Information/human/000885/WC500052310.pdf - accessed November $201 \overline{4}$.

7. Matsuki G, Takahata O, Iwasaki H (2011) Repeat dosing of rocuronium after reversal of neuromuscular block by sugammadex. Can J Anaesth 58: 769-770. [Crossref]

8. Cammu G, de Kam PJ, De Graeve K, van den Heuvel M, Suy K, et al. (2010)
Repeat dosing of rocuronium $1.2 \mathrm{mg} \mathrm{kg}-1$ after reversal of neuromuscular block by sugammadex $4.0 \mathrm{mg} \mathrm{kg}-1$ in anaesthetized healthy volunteers: a modelling-based pilot study. Br J Anaesth 105: 487-492. [Crossref]

9. https://www.medicines.org.uk/emc/medicine/5166 - accessed November 2014.

10. Kim YH (2014) Repeat dosing of rocuronium-sugammadex: unpredictable. Korean $J$ Anesthesiol 67: 1-3. [Crossref]

11. Bom A, Hope F (2005) Neuromuscular block induced by rocuronium and reversed by the encapsulating agent Org 25969 can be re-established using the non-steroidal neuromuscular blockers succinylcholine and cis-atracurium. Eur J Anaesth 22 (Suppl 34):120.

12. Barclay K, Eggers K, Asai T (1997) Low-dose rocuronium improves conditions for tracheal intubation after induction of anaesthesia with propofol and alfentanil. $\mathrm{BrJ}$ Anaesth 78: 92-94. [Crossref]

Copyright: (C2015 Real C. This is an open-access article distributed under the terms of the Creative Commons Attribution License, which permits unrestricted use, distribution, and reproduction in any medium, provided the original author and source are credited. 